\title{
Medical Educators' Beliefs about the Alignment of Learning Goals, Teaching, and Assessment in the Context of Curriculum Changes: A Qualitative Study Conducted at an Iranian Medical School
}

Morteza Karami ( $\nabla$ m.karami@um.ac.ir)

Ferdowsi University of Mashhad https://orcid.org/0000-0002-7161-9500

Nooriyeh Hashemi

Eshraq University

Jeroen van Merrienboer

Maastricht Universitair Medisch Centrum+ Anesthesie

Research article

Keywords: Medical Educators' Beliefs, Learning Goals, Teaching Methods and Assessment Methods

Posted Date: January 22nd, 2021

DOl: https://doi.org/10.21203/rs.3.rs-57511/v2

License: (c) (i) This work is licensed under a Creative Commons Attribution 4.0 International License.

Read Full License 


\section{Abstract}

Background: Achieving changing needs, advancing knowledge, and innovations in higher education require the constant changes of medical school curricula and successfully applying the new reforms requires some modifications in the medical educators' core beliefs. The purpose of this study was to describe the medical educators' beliefs about the alignment of the learning goals, teaching and assessment in the context of the curriculum changes.

Method: A qualitative method was used to study the medical educators' beliefs by selecting the faculty participants via a purposeful sampling strategy. This study was conducted at a Medical School in Iran. For the individual interviews, we invited both the professors of the basic sciences and the clinical professors who had worked with the medical students for at least five years. Ten educators were interviewed.

Result: The results of the research show that the professors believe that the development of competencies has been abandoned and this is due to the priority of treatment to education in the clinical course and the limited learning experiences. Moreover, the gap between the content and the context and the practicing in the hospital instead of the clinics has reduced the authenticity of the learning environment this situation, and has affected its quality. The non-systematic assessment has also helped to establish.

Conclusion: The compartmentalization of the curriculum and the structure of the medical education have caused the beliefs of the professors to be in line with the past perspectives, despite the change in the curriculum, and a change in the structure of the curriculum is necessary to change them.

\section{Background}

Changes in education, including the curriculum and modes of teaching and learning, have been a major focus of higher education. Society's changing needs, advancing knowledge (Khan, Khawaja, Waheed, Rauf, Fatmi, 2006), and innovations in education (Dagher, Atieh, Soubra, Khoury, 2016) require the constant changes of medical school curricula [1], [2]. In line with these changes, problem-based curricula and, more recently, competency-based curricula have become common. Earlier, curricula were often subject- or discipline-based [3], but, nowadays, they often focus on the problems or tasks that appeal to to-be-developed competencies. This curriculum change has significant implications for teaching and assessment, which requires teachers to be engaged in more complex practices [4]. 'Outcomes-based teaching and learning' is a well-suited approach to create alignment between the components of curriculum [5]. Regarding this approach, competencies are the outcomes of learning, and teaching should be designed in a way that engages students in learning activities which lead to those outcomes. Assessment, then, addresses how well those outcomes have been achieved by students [6]. Constructive alignment is a form of outcomes-based teaching and learning in which both teaching and assessment are aligned with the intended learning outcomes [5], [7]. 
In problem-based and competency-based curricula, learning goals are concentrated on the competencies that students must be able to apply in the real world context, and teachers' practices should thus require students to develop the competencies necessary to complete meaningful tasks and to solve problems [8]. Such complex tasks typically appeal to a variety of competencies; that is, they require the integration of multiple objectives[9]. Whole-task approach to teaching [10], [11] provide an appropriate model for the development of the educational programs that help students learn and transfer professional competences to an increasingly varied set of real-world contexts and settings. It also helps students in their future career endeavors[12]. Based on the theoretical models in this field such as the first principles of instruction[13], [14] and the four-component instructional design model[15], the backbone of learning environment is to provide whole learning task based on real-world problems from simple to complex. The learner is supported in the process of performing these tasks and this support is diminished and faded as the learner progresses. Learning and practicing in such environments provide a better context for learning transfer.

The competencies to be learned are introduced as early as possible through different learning tasks that appeal to those competences [16]. The final attainment levels are often described in terms of the standards that must be reached for each of the to-be-acquired competencies [11]. In outcomes-based teaching and learning, assessment is criterion referenced. Student performances are assessed by judging them against established grading criteria or rubrics. In constructive alignment, the logic of assessment is holistic, not analytic [5].

Implementation is critical to the success of a new curriculum. This step converts a mental exercise to reality [17]. Teachers, as the main agent in educational change, play a vital role in the successful implementation of new curriculums [18]. They, responsible for enacting curriculum decisions, hold beliefs that can support or undermine how learners experience these decisions and their activities are shaped by their beliefs [19]. Accordingly, teachers' beliefs have been viewed as a key issue in the context of most educational reforms [20]. One possible explanation for the incomplete implementation of the ideal curriculum may be found in teachers' beliefs [1]. Therefore, research on teachers' beliefs is seen as a key area that needs to be addressed in the context of educational reforms [20].

Teachers, as all humans do, hold beliefs about a variety of topics, relationships, and processes[21]. Their beliefs shape their real behavior towards their learners [22], [23]. Beliefs play a significant role in determining how educators organize knowledge and information, that is, they signify the most unchanging and least flexible dimension of an individual's view on teaching' [24]. Teachers' beliefs refer to an integrated system of judgments that relate to teachers' classroom work [25]. They can help students to convey their experiences more explicitly (Siemens, Punnen, Wong, \& Kanji, 2010; Sukhato et al., 2016).

In sum, teachers' beliefs and practices play a key role in curricular reforms because teachers are the performers of educational change [26], [27], and policymakers, university leaders, department heads, and teacher educators must attend to teachers' beliefs as part of any change efforts. Despite the growing trend of recognizing the importance of teaching beliefs, little substantive research exists, specifically in 
medical education, about how medical educators adjust their beliefs to curriculum change. This lack of research is problematic for, at least, two reasons. First, it is common for medical faculty to have little if any preparation in their role as teachers. Usually, their development as teachers is through a series of 'trial by fire' experiences with lectures, tutorials, and clinical teaching. Little time is spent reflecting on underlying beliefs about teaching. Second, educators in a competency-based curriculum have different responsibilities. Their beliefs and practices should be aligned with learning goals and to reach those goals, educational interventions for teaching complex tasks are needed [28].

\section{Methods}

This qualitative study was undertaken, using in-depth, semi-structured interviews with the ten medical educators of the general medicine program at the Medical School of Mashhad University of Medical Sciences, Mashad, Iran. To identify and select the participants, a purposeful sampling strategy was used as shown in Table 1. For the individual interviews, we invited both the professors of basic sciences (such as biochemistry, physiology, and anatomy) and the clinical professors (the professors of externship and internship) who had worked with the medical students for at least five years.

Table 1

Characteristics of the participants

\begin{tabular}{|ll|}
\hline Educators $(\mathrm{N}=10)$ & \\
\hline Characteristic & Description \\
\hline men & 8 \\
\hline women & 2 \\
\hline Professors of basic department & 5 \\
\hline Professors of clinical department & 5 \\
\hline Work Experience & More than 5 years \\
\hline Age & $40-60$ \\
\hline
\end{tabular}

\section{Study Context}

This study was conducted at a Medical School in Iran. In 2015, Iran's Ministry of Health and Medical Education (MHME) announced that the institutions of higher education must ensure that all graduates of the medical programs can demonstrate professional commitment, decision-making, and problem solving (clinical skills), as well as communication skills, sensitivity to caring for patients, self-regulated skills for individual development or continuous learning, and the ability to improve community health. Recently, with an emphasis on expanding the role of family doctors, the re-design of the programs for preparing medical doctors has become more critical in the medical education system in Iran. Therefore, to meet the 
new educational aims, a new curriculum was modernized in 2017 by introducing the core competencies. Mashhad University of Medical Sciences is one of the best universities in Iran which has 25 clinical and 19 basic departments. The research was conducted on the medical school curriculum revised in 20172018.

\section{Data Collection}

The professors were informed collectively about the interviews and were invited for individual interviews with one of the researchers. The interviews with the professors of the basic sciences were conducted in the department of medical education at Mashhad University of Medical Sciences and the interviews with the clinical professors were conducted in Imam Reza hospital. Each interview lasted for 45 to 60 minutes. All interviews were recorded and transcribed verbatim. All data were kept confidential and were accessible to the investigators. The participants signed the informed consent forms. Two departments were involved in the data collection: we interviewed 10 professors ( 5 from the basic sciences department and 5 from the clinical department). After each individual interview, we checked whether new information had emerged. Interviewing continued until saturation was reached.

\section{Data Analysis}

Three successive phases were used to analyze the interviews based on Miles and Huberman's theory (2003) about qualitative data analysis: data reduction by coding, data structuring by categorization, and data interpretation by discussion. $\mathrm{NH}$ imported all interview transcripts into the MAXQDA software package and coded all items. The codes were used as the first coding dictionary. MK revised the coding dictionary by removing the code duplicates and discussing the codes. MK and JvM structured the codes and discussed their structures to identify the dimensions of the learning goals, teaching, and assessment. The data interpretation via discussion was the connecting activity throughout the whole analysis process and during the decision-making process about the relevant quotes.

\section{Results}

In this section, we will describe the teachers' beliefs about the alignment of learning goals, teaching, and assessment. The interview data provided a detailed and clear understanding of the participants' beliefs about teaching in the medical contexts, and the results are discussed below:

\section{Limited Learning Opportunities}

Most of these medical educators(7/10) believed learning opportunities were limited; however, they were trying to point out the relevant and important information in the context to facilitate real learning. For example, Participant (B2) stated:

"The syllables in the course are defined and I use slides to present the lessons. I try to give clinical examples. For example, when talking about enzymes, I say anti-enzyme drugs that are related to the 
treatment of diseases. Because the students were doing their homework based on online copying and it had become something formal, I stopped giving homework to the students."

Also, Participant C3 recognized that:

"The number of students is large, almost 100 people in the basic courses and there is no possibility of active methods such as discussion because there is no necessary interaction. Mostly the contents are presented as lectures. Yet, this is a good form of presentation. If the teacher just read the slides, it would be worse."

According to most professors' views, the lack of time and the large volume of the materials lead them to employ the teaching methods that are more efficient and allow them to present more materials in the class.

\section{The Ignorance of the Core Competencies in Learning Processes and Assessment}

The most important change in the new curriculum is the addition of professional competencies, but the professors $(9 / 10)$, despite acknowledging the importance of this issue, believe that this is not taken into account in the teaching-learning processes for various reasons, including the large number of students and the large volume of the materials.

Accordingly, Participant C1 stated:

"The education system in the medical context is complex. A large number of students attend in one class and in this situation, how a teacher can communicate well with all of them in a limited time and how can s/he manage them to acquire the core competencies?!"

Accordingly, Participant B2 stated:

"In different courses, we try to use the main up-to-date resources that are comprehensive and contain a lot of content, in teaching. It is very difficult to present all these materials during the semester sessions and, therefore, there is no opportunity for other learning activities."

Another reason is that the professors believe that since there are specific courses for these competencies, it is not necessary to address those competencies in other courses. For example, Participant B4 says:

"We specifically have a course in the curriculum to teach effective communication, professional ethics, and so on. The student can acquire these skills there, and the mission of my course is something else. We no longer need to address these issues in different courses. Teaching thinking skills should also be included as a compulsory course in the curriculum; however, its teaching method can be different. One can talk about his experiences, one can show a film, but it should be one of the compulsory courses."

What emerges from the interviewees' opinions is that there is a large gap between the intended and implemented curriculum, and despite the existence of attention to these competencies in the curriculum 
document, the professors are not very faithful to it in action

\section{The Gaps between Content (Class) and Context (Workplace)}

The medical educators $(8 / 10)$ believed that the value of the contents are not well appreciated by the students because they have not been given the opportunities to put what they have learned into practice immediately Participant (B3) stated:

"General physician students are not willing to take the basic sciences. When I myself was a medical student and I was going through an internship, I had the same belief as the current students. The belief is that the basic sciences are very inefficient courses that just has to be passed and finished to enter the physiopathology. What if the structure of a molecule has 4 rings?"

In addition, Participant (B5) explained:

"Most of the students don't know about the philosophy of the subjects they are studying; however, some of the chosen content is not much related to the real world that the students will experience in the context. The students study heavy content in their theoretical courses, but they do not have enough o opportunities to acquire the needed competencies in their workplace."

Thus, while the content is primary, it needs to be put into practice in the context. These educators believe that one of their roles as university professors is to help the learners discern from the vast amounts of content knowledge the required information they need to apply to specific real-world cases in workplace. .

It should also be mentioned that both the basic sciences educators and the clinical educators believed that the context of the medical school is more atomistic rather than to be holistic and there is a disconnection between the basic knowledge and the clinical sciences

\section{Non-systematic Assessments}

Most professors (6/10) believe that the current conditions do not allow them to use high-level tests. The professors of the basic courses believe that the large number of students does not provide an option other than multiple-choice tests, and the professors of the clinical courses also consider the high workload as the main reason for this problem. The analyses of the data collected via the interviews highlighted the following issues:

"The assessment is conducted based on the book content and we usually don't give practical tests in the basic courses because applying practical tests in crowded classes is a complex process." (Participant B1)

"The high workload in the ward and the large number of intern students in the ward prevent us from conducting a comprehensive and systematic assessment of the student." (Participant C2)

Most of the medical educators believed that the traditional method of assessment was used by most of the teachers. For example, Participant B2 remarked: 
"I feel that the knowledge of making a test is one way that makes a teacher unique and the teachers should consider it. Unfortunately, we usually assess the students by giving multiple-choice tests because the classes are crowded and it is difficult to check 100-150 papers at once; however, from the last year we have started to give open ended tests to the students."

Despite the importance that assessment can have in the educational system and the relative awareness that professors have of this issue, the executive conditions have caused professors to spend less energy on accurate and systematic testing of students.

\section{Practicing in Hospitals instead of Clinics}

The findings obtained from the medical educators $(8 / 10)$ indicated that the GPs were practicing in the hospitals. This group of medical educators found that practicing the GPs in specialized hospitals was an important challenge. They believed that the GPs needed to work in clinics or specialized labs for their practical experiences. Participant (C1) stated:

"The educational system is designed according to the MD system for both MD and GP students with the same content. In fact, they study the same content but their work positions are completely different. The $M D s$, after entering a specialized medical course, have a good work position in the future with a high salary but the GPS don't have such a good position."

Similarly, Participant C5 recognized:

"On the practical level, Students go to the specialized hospitals for internships, but these environments are different from the real work environment of a general practitioner. working in a particular ward can assist the students to have a better understanding of that ward. It may also help them to plan their professional development better. The educational system should consider the possible ways to prepare appropriate learning orientations for the GPs."

Most professors believe that what are functional expectations from a general practitioner are not learned in the various wards of a specialized hospital, and that these learning environments pose a serious challenge in terms of authenticity.

\section{Clinical Work Preference Rather than Teaching}

The findings obtained from the educators' beliefs $(5 / 10)$ indicated that teaching competed with many other demands and took place in a context that had constant distractions out of the control of the professors. Participant (B4) explained:

"I feel like I have so much stuff that I just want the students to understand, that I just want them to pass their course and I don't feel I have the time to teach efficiently. Some days I have clinic in the afternoons, so I am running back and forth."

Furthermore, Participant C5 stated: 
"Our hospital is the largest and most important hospital in the city and is always full of patients who need care. For us, the patient is a priority, even in educational rounds, because of the patients, we cannot pay attention to many aspects of education."

But in each of these educators' remarks quoted above, treatment is preferable to teaching. This has led to learning in clinical learning environments not being in line with the pre-designed goals and activities.

\section{Discussion}

This study in particular focused on what the medical educators' beliefs are about teaching, learning, and assessment in the context of the curricular change and it brought greater clarity to the influence of the core beliefs held by the medical educators.

The findings of this study helped to answer our research questions and show that...

The findings of this study helped to answer our research questions and show that the participants in this study share a set of core teaching, learning, and assessment beliefs that shape their practices as teachers. The results of the research show that the professors believe that the development of competencies has been abandoned. They consider it as a result of the inadequate quantity and quality of experiences in the learning environment. The high volume of content and large number of students in the basic course and the priority of treatment to education in the clinical course have caused limited learning experiences. Furthermore, the gap between the content and the context and the presence in the hospital instead of the clinic has decreased the authenticity of the learning environment and has influenced its quality. The unsystematic assessment has also aided to establish this condition.

The medical educators believed that the gaps between the theoretical contents and the real-world settings is one on the reasons to ignore the core competencies in the learning and assessment processes. This issue could be due to the fact that the basic courses such as physiopathology, anatomy, biochemistry, etc. and the clinical courses are presented in the form of $\mathrm{H}$ model[1]. More specifically, in this model students pass all their basic courses inside the class without getting any experience in the practical courses and then go to the hospitals as interns. Following this model causes the gaps between what the students learn in the class and what they need to know and, especially, do in the hospitals. Learning in such an educational climate is knowledge-based rather than competency-based.

It should also be mentioned that the first years mainly focus on the basic sciences while the subsequent years deal exclusively with the clinical education and skill training. In this way, learning is believed to be a simple accumulation of knowledge and the basic sciences are focused on in a preclinical phase usually lasting four years. Every basic science is presented in an isolated course and there is little or no integration across disciplines [29].

Professors believe that in the clinical settings, treatment takes precedence over education. Of course, this situation seems to be due to the nature of the treatment environment. According to Irby et al. (2010), the 
medical training is inflexible, overly long, and not learner-centered. The clinical education for both the students and the residents excessively emphasizes the mastery of facts, inpatient clinical experience, teaching by residents, and supervision by clinical faculty who have less and less time to teach, and hospitals with marginal capacity or willingness to support the teaching mission. They observed poor connections between formal knowledge and experiential learning and inadequate attention to the patient populations, health care delivery, patient safety, and quality improvement. The learners lacked a holistic view of patient experience and they poorly understood the broader civic and advocacy roles of physicians. Finally, the pace and commercial nature of health care often impede the inculcation of the fundamental values of the profession [30].

Despite their emphasis on content, the medical educators believed that the learning opportunities were limited, and assessment is also carried out in a non-systematic manner. These were the consequence of the lecture-dominated curriculum. In this approach, the learning processes were mainly the results of direct teaching. In a lecture-dominated curriculum with limited or no clinical experiences, students have few opportunities to observe the professional demeanor or actions of practitioners and thus have no role models to emulate. Later, as more laboratories and clinical experiences are introduced, there is still no formal focus on the development of professional competencies and professional identity.

The professors believed that the presence of students in the specialized hospitals made them unable to learn the skills required for a general practitioner. To enhance the authenticity of the learning environments, students should attend the clinic instead of the hospital. The use of authentic learning (i.e., connecting knowledge to real-world issues, problems, and applications) is a powerful learning strategy. The competency-based approach allows learners to practice seven core skills, namely, clinical skills, communication skills, caring of patients, health development, individual development, professional commitment and decision making, and reasoning and problem solving. If the development of these complex skills is integrated into the learning processes, the learners will be more likely to transfer the skills to the real-world settings later. To this aim, the task-based learning approach is a suitable choice. In the task-centered learning environments, it is the real-world problems or tasks that drive learning [15], [31].

Integration in medical education is important because the medical practice itself requires a great deal of integration. Integration refers to the connection of formally structured knowledge of the basic, clinical, and social sciences with clinical experiences in a much more balanced manner than it occurs today [32]. Integration promotes the blending of the basic sciences with each other, as well as with the clinical sciences. The benefits of integration are attributed to presenting information and problems in a way that mimics how they are encountered in the real world and presenting facts in relevant, meaningful, and connected ways. Integration should be viewed as a strategy of curricular design and development and; therefore, it should be considered at the program, course, and session levels [33].

Footnote: 
[1] The traditional curriculum can be represented by an $\mathrm{H}$ shape structure, with all clinical sciences presented later in the curriculum. In this model, students study all their basic subjects inside the class and, then, continue the clinical sciences outside.

\section{Conclusion}

Kern's six stages are frequently employed as a guide to design curricula. These are: 1) Problem identification and general needs assessment, 2) Needs assessment for targeted learners, 3) Goals and objectives, 4) Educational strategies, 5) Implementation, and 6) Evaluation and feedback [17]. Nonetheless, curricular change is not merely concerned with the technical pedagogical dimension. Reform, particularly in an intricate system like a medical school, is full of problems such as resistance, power, inertia, and ego challenges which necessitate a planned method, as well [34].

Teachers' beliefs show the inconsistencies between the intended and implemented curriculum and the non-alignment between goals, methods, and assessment. The compartmentalization of the curriculum, the large number of students, the large volume of the instructional materials, and the nature of the clinical settings are the main causes of this inconsistency.

Therefore, to achieve an integrated learning context, the current beliefs of teachers need to be further changed to realize more integrated learning in the future. They should connect the basic sciences to the clinical sciences and add the core competencies in their lesson plans. Moreover, the academic members of medical schools should revise the medical school curriculum by applying an inter-discipline approach, holding instructional seminars, and analyzing successful consequences to apply them as appropriate interventions.

\section{Strengths and limitations}

We used a qualitative method to collect and collate the teachers' beliefs in the learning goals, teaching methods, and assessment methods in the context of curricular changes. To the best of our knowledge, this is the first research in medical education to address these issues.

Our study suffers from some important limitations. Firstly, as all participants were from a Family Medicine Department, their beliefs might not be generalized to the faculties in other fields and settings. Due to these limitations, further studies should assess whether the perceived benefits and concerns we discovered would be similar among teachers in different settings and fields of practice. Secondly, all teachers participating in this study were Iranian and their expression of feelings may differ from teachers in other cultures. Lastly, the potential for the interviewer's bias might have influenced the views of the participants during the interviews. We attempted to reduce this possibility by limiting their dialogues to the questions and the clarifications, and by instructing them to avoid expressing the opinions.

\section{Implications}


Several implications arise from our study. Most of the medical educators believed that the learning outcomes and the assessment methods were not aligned with the curricular changes. Learning outcomes and assessment methods must be aligned; therefore, integrated learning must be assessed in an integrated manner. Furthermore, a change towards more active methods and a whole-task approach to teaching and assessment are needed to help students acquire the desired skills. Finally, teachers should be given ongoing support, including the provision of feedback on individual performance.

\section{Abbreviations}

GP: General Practitioner

MD: Medical Doctor

MHME: Iran's Ministry of Health and Medical Education

\section{Declarations}

\section{Ethics Approval and Consent to Participate}

This study was carried out in Iran in accordance with the applicable rules concerning the review of research ethics committees and informed consent (The Research Ethics Committee of the Mashhad University of Medical Sciences University).

\section{Consent for publication}

“Not applicable”

\section{Availability of data and materials}

Data will not be shared due to restrictions stipulated by the ethics committee when approving the study.

\section{Competing interests}

The authors declare that they have no competing interests

\section{Funding}

Not applicable

\section{Authors' contributions}

$\mathrm{NH}$ imported all interview transcripts into the MAXQDA software package and coded all items and was a major contributor in writing the manuscript. MK interviewed with all participants and revised the coding dictionary by removing code duplicates and discussing the codes. MK and JvM structured the codes and 
discussed their structures in order to identify dimensions of learning goals, teaching and assessment. All authors read and approved the final manuscript.

\section{Acknowledgements}

Not applicable

\section{References}

El Achi, D., Al Hakim, L., Makki, M., Mokaddem, M., Abi Khalil, P., Kaafarani, B. R., \& Tamim, H. (2020). Perception, attitude, practice and barriers towards medical research among undergraduate students. $B M C$ medical education, 20(1), 1-11.

[1] S. Cerimagic, "Changing medical education curriculum: challenges, preparation and implementation of change," Sustain. Ecol. Eng. Des. Soc. Int. Conf., pp. 6-7, 2018.

[2] C. J. Bland, S. Starnaman, L. Wersal, L. Moorhead-Rosenberg, S. Zonia, and R. Henry, “Curricular change in medical schools: How to succeed," Acad. Med., vol. 75, no. 6, pp. 575-594, 2000, doi: 10.1097/00001888-200006000-00006.

[3] P. Midlöv, P. Höglund, T. Eriksson, A. Diehl, and G. Edgren, "Developing a Competency-based Curriculum in Basic and Clinical Pharmacology - A Delphi Study among Physicians," Basic Clin. Pharmacol. Toxicol., vol. 117, no. 6, pp. 413-420, 2015, doi: 10.1111/bcpt.12436.

[4] H. Fives and M. M. Buehl, "Teachers' Beliefs, in the Context of Policy Reform," Policy Insights from Behav. Brain Sci., vol. 3, no. 1, pp. 114-121, 2016, doi: 10.1177/2372732215623554.

[5] J. Biggs and C. Tang, "Constructive alignment: An outcomes-based approach to teaching anatomy," in Teaching anatomy, Springer, 2015, pp. 31-38.

[6] J. Biggs, "Aligning teaching and assessing to course objectives," Teach. Learn. High. Educ. New trends Innov., vol. 2, no. April, pp. 13-17, 2003.

[7] S. Nightingale, A. L. Carew, and J. Fung, "Application of constructive alignment principles to engineering education: have we really changed?," 2007.

[8] D. H. J. M. Dolmans, I. H. A. P. Wolfhagen, and J. J. G. Van Merriënboer, "Twelve tips for implementing whole-task curricula: How to make it work," Med. Teach., vol. 35, no. 10, pp. 801-805, 2013.

[9] J. J. G. van Merriënboer and I. Tjiam, "Development and teaching of complex skills in invasive procedures," in Catheter-Based Cardiovascular Interventions, Springer, 2013, pp. 173-186.

[10] G. M. Francom and J. Gardner, "What is task-centered learning?," TechTrends, vol. 58, no. 5, pp. 2735, 2014. 
[11] J. J. G. Van Merriënboer and L. Kester, "Whole-task models in education," Handb. Res. Educ. Commun. Technol., vol. 3, pp. 441-456, 2008.

[12] D. El Achi et al., "Perception, attitude, practice and barriers towards medical research among undergraduate students," BMC Med. Educ., vol. 20, no. 1, pp. 1-11, 2020.

[13] M. D. Merrill, “First principles of instruction,” Educ. Technol. Res. Dev., vol. 50, no. 3, pp. 43-59, 2002.

[14] M. D. Merrill, First principles of instruction. John Wiley \& Sons, 2012.

[15] J. J. G. Van Merriënboer and P. A. Kirschner, Ten steps to complex learning: A systematic approach to four-component instructional design. Routledge, 2017.

[16] A. P. Susilo, J. van Merriënboer, J. van Dalen, M. Claramita, and A. Scherpbier, “From lecture to learning tasks: use of the 4C/ID model in a communication skills course in a continuing professional education context," J. Contin. Educ. Nurs., vol. 44, no. 6, pp. 278-284, 2013.

[17] P. A. Thomas, D. E. Kern, M. T. Hughes, and B. Y. Chen, Curriculum development for medical education: a six-step approach. JHU Press, 2016.

[18] M. Fullan, The new meaning of educational change. Routledge, 2007.

[19] N. M. Ahsan and T. Anjum, "A study of Pakistani teachers' beliefs and perceptions about teaching and learning," Interdiscip. J. Contemp. Res. Bus., vol. 4, no. 5, pp. 128-143, 2012.

[20] W. A. Hoy, H. Davis, and S. J. Pape, “Teacher knowledge and beliefs," 2006.

[21] H. Fives and M. M. Buehl, "Spring cleaning for the 'messy' construct of teachers' beliefs: What are they? Which have been examined? What can they tell us?," 2012.

[22] A. Hargreaves, M. B. Shinde, and T. K. Karekatti, "PRE-SERVICE TEACHERS ' BELIEFS ABOUT TEACHING," vol. 5, no. 1, 2012.

[23] E. Aflalo, "Learning approach and learning strengths: A case study in an ultraorthodox community," Issues Educ. Res., vol. 22, no. 3, pp. 201-212, 2012.

[24] E. W. Taylor, E. J. Tisdell, and M. E. Gusic, "Teaching beliefs of medical educators: Perspectives on clinical teaching in pediatrics," Med. Teach., vol. 29, no. 4, pp. 371-376, 2007, doi:

10.1080/01421590701510553.

[25] C. Peck and L. Herriot, Teachers'Beliefs About Social Studies. 2015.

[26] G. Hall and S. Hord, "Implementing change: Patterns, principles, and potholes 4th ed." Upper Saddle River, NJ: Pearson, 2015. 
[27] E. M. Rogers, Diffusion of innovations. Simon and Schuster, 2010.

[28] J. Tondeur, J. Van Braak, P. A. Ertmer, and A. Ottenbreit-Leftwich, "Understanding the relationship between teachers' pedagogical beliefs and technology use in education: a systematic review of qualitative evidence," Educ. Technol. Res. Dev., vol. 65, no. 3, pp. 555-575, 2017.

[29] E. Bergman and A. de Goeij, "Basic sciences in problem-based learning," Lessons from Probl. Learn., vol. 57, p. 65, 2010.

[30] D. M. Irby, M. Cooke, and B. C. O’Brien, "Calls for reform of medical education by the Carnegie Foundation for the Advancement of Teaching: 1910 and 2010," Acad. Med., vol. 85, no. 2, pp. 220-227, 2010.

[31] G. M. Francom, "Principles for task-centered instruction," in Instructional-Design Theories and Models, Volume IV, Routledge, 2016, pp. 81-108.

[32] D. Irby, "Educating physicians for the future: Carnegie's calls for reform," Med. Teach., vol. 33, no. 7, pp. 547-550, 2011.

[33] J. E. Ilkiw, "integrated learning," in Veterinary Medical Education: A Practical Guide, 2018.

[34] S. Reis, "Curriculum reform: Why? What? How? and how will we know it works?," pp. 7-10, 2018. 